\title{
Social Acceptability, Obstructions, Collaboration and Embarrassment
}

\author{
Robb Mitchell \\ University of Southern Denmark, Kolding, 6000, Denmark \\ robb@sdu.dk
}

\begin{abstract}
This position paper outlines my interest in socially acceptability and embarrassment as explored through low-tech interaction design undertaken in urban spaces, art galleries, industrial innovation events and games workshops. ${ }^{1}$
\end{abstract}

\section{Keywords}

Social interaction · facilitation · breaching experiments · interactive art

\section{Introduction}

In my experience, design experimentation that stretches the normal boundaries of social acceptability can actually lead to increasing, rather than diminishing the conviviality of a setting. Disrupting expectations of behaviours may spark novel exchanges, expressive play and lead to new ideas for people effected,

1 This article is based upon a CHI2015 workshop position paper that was uploaded to the webpage of the Embarrassing Interactions workshop.

How to cite this book chapter:

Mitchell, R. 2020. Social Acceptability, Obstructions, Collaboration and Embarrassment. In: Loizides, F., Winckler, M., Chatterjee, U., Abdelnour-Nocera, J. and Parmaxi, A. (eds.) Human Computer Interaction and Emerging Technologies: Adjunct Proceedings from the INTERACT 2019 Workshops. Pp. 111-116. Cardiff: Cardiff University Press. DOI: https://doi.org/10.18573/book3.m. License: CC-BY 4.0. 
whilst also offering a means for designers and researchers to better understand social situations.

My work is interaction design in the broader sense of the term. I do not view cutting edge technology as a prerequisite for exploring social issues in HCI. As the social media theorist Clay Shirky puts it: "Communications tools don't get socially interesting until they get technologically boring" [12].

Working across a variety of domains such as interactive arts, participatory design and event curating. I have devised artifacts, environments, processes, systems and events that aimed to help bring people closer together creatively, socially and professionally. In particular, addressing the barriers between: remote locations; different disciplines; experts and non-experts; and other colocated people who are not yet acquainted with each other.

\section{Embarrassment as an interpersonal shield}

The notion of barriers connects with the etymology of the word embarrassment, i.e. its origins in meaning obstruction. Although never an implicit aim, the powerful phenomenon of embarrassment has played a major role in many previous projects. Several themes concerning different connections between senses of embarrassment, obstruction and fostering positive co-located encounters are briefly discussed in the following.

\subsection{Amplify awkwardness until it disappears}

Embarrassment is relational - to be embarrassed normally involves a sense of negative imbalance of emotions such as dishonor or shame compared with other people. Having a witness to getting stuck in a typical revolving door would thus be an embarrassing experience for many people. However with a turnstile resembling social contraptions such as Blender, and Heads Up of The Table all participants found the artifact challenging to their movements. If disconcertment is universal within a context, then the potential for embarrassment is much reduced.

Both these contraptions are part of series of art installations that were designed to foster positive face-to-face interactions between strangers who may not otherwise interact [7]. Each contraption presented participants with a shared physical obstacle. This was intended to create a situation in which there are less predetermined "rules" concerning how to behave. Providing a novel constraint on "normal" behaviour was intended as a route to partially dissolve the everyday norms (both internal/individual and social/collective) that may inhibit social interactions between the unacquainted. This in turn, could provoke and encourage a fluidity of interaction between strangers. 


\subsection{Surfacing social design challenges}

Human surrogates deployed to act as walking, talking avatars [9] may also offer insights relevant for understanding social (un) acceptability and embarrassment. These low-tech interventions can open up for discussion issues such as adaptation, control, visibly, accountability, sharing and differences in participant roles. Paradoxically, in comparison with digital social systems, the contraptions seem to move both towards making people's responses into a "material" that is visible and tangible. However, at the same time, in provoking a wide variety of unpredictable responses the contraptions make vivid how this is a tangibility that eludes a firm grip and is thus a visibility that both illuminates and obscures [10].

\subsection{Breaching embarrassment to \& from public collaboration}

While physical constraints have long been exploited as a design tactic or inspiration in the overall quest for a more human-centered design and development process, another intuitive quality of interaction has been somewhat overlooked, namely that of social constraints and the instinctive social behavior of people [6].

Ordinary social order impedes attempts by technologists to provoke disparate individuals to collaborate or share experiences in urban public spaces. To address these barriers we analysed responses to a number of city center social interventions inspired by the sociological concept of breaching experiments.

In these cases, embarrassment was prominent in three ways. Firstly, and not surprisingly, it was detectable in the responses of passers by to the performed "breaches". Secondly, many of the students that devised and implemented these interventions reported great initial embarrassment before the public implementation of their experiments. And thirdly, the sense of embarrassment was profound when we as researchers sat down to watch video recordings of several of the interventions. For instance, watching documentation of students sit down at the café tables of strangers and making small talk prior to performing their "breach" of asking if they can taste the food on the strangers' plate [6] was particularly excruciating at times.

\subsection{Unacceptable interactions to prompt more acceptable behaviours}

I am proud to have been involved in supporting some recent student work with mechatronical furniture that also provokes and reveals issues of embarrassment. For instance a toilet brush that attempts to build a relationship with people sitting on the lavatory [1] and tables that respond to different 
speeds at which companions eat [10] or the speed at which people approach it [2]. Designs such as these offer potential both as research vehicles into social contexts and as a means of harnessing socially awkward experiences towards motivating behaviour change [2].

\subsection{Clumsy mishaps breed insightful excuses}

Based upon a survey of several years of innovation workshop activities focused upon fostering shared understanding of business challenges [5], we developed an argument for the value of "Oops! Moments" [8]. By which we mean the surprise and uncertainty evoked by the use of 'kinetic materials' (e.g. bouncing balls, springs, and seesaw like mechanisms) in business strategy discussions may facilitate fresh and spontaneous exchanges of perspectives.

To avoid potential embarrassment when being seen as unable to manipulate physical objects according to their intentions and expectations, workshop participants often improvise creative and humourous explanations that inadvertently serve to enliven and enrich shared sensemaking concerning innovation challenges [8].

\subsection{Sensory deprivation prompts embarrassment}

Blocking a perceptual channel of participants can contribute to increasing both bodily expressivity and vocalizations that might be considered prohibitively undignified under other circumstances.

Reindeer and The Wolves is a digital movement based game that features two blindfold participants in physical pursuit of three other players. Obstructing the perceptual channel of sight appeared to release players to perform expressive bodily actions and vocalizations that might be considered prohibitively undignified under most other circumstances [3]. However we could discern little sign of embarrassment amongst participants and audience.

For a person's action to be considered embarrassing, it is commonly understood that another person should either witness it, or come to know about it through some indirect means. This can help to explain how non-blindfold players felt free to act ignominiously towards their non-sighted competitors. However, it is interesting that blindfolded players themselves also performed very self-demeaning actions. It was as if the lack of two-way contact with witnesses to undignified actions serves to remove or reduce what would otherwise be their embarrassing qualities.

\section{References}

1. Boer, L., Hansen, N., Möller, R.L, Neto, A.I.C., Nielsen, A.H., and Mitchell, R. The Toilet Companion: A toilet brush that should be there for you and not for others. In: Proc. Augmented Human Conference, ACM (2015). 
2. Boer, L., Mitchell, R., Caglio, A., and Lucero, A. Embodied Technology: Unravelling Bodily Interaction with Normative Types. In: CHI'15 Extended Abstracts, ACM (2015).

3. Finnegan, D., Velloso, E., Mitchell, R., Mueller, F.F., and Byrne, R. Reindeer \& Wolves: Exploring Sensory Deprivation in Multiplayer Digital Bodily Play. In: Proc. CHI Play, pp. 411-412. ACM (2014).

4. Koelle, M., Boll, S., Olsson, T., et al. (2018) (Un) Acceptable!: Re-thinking the Social Acceptability of Emerging Technologies. In: Extended Abstracts of the 2018 CHI Conference on Human Factors in Computing Systems. ACM.

5. Heinemann, T., Boess, S., Landgrebe, J., Mitchell, R., \& Nevile, M. (2011, October). Making sense of things: developing new practices and methods for using tangible materials in collaborative processes. In: Desire'11 Proceedings of the Second Conference on Creativity and Innovation in Design, pp. 221-225. ACM (2011).

6. Heinemann, T., and Mitchell, R. Breaching barriers to collaboration in public spaces. In: Proc. TEI '14, pp. 213-220. ACM (2014).

7. Mitchell, R. Physical contraptions as social interaction catalysts. 3rd International Workshop on Physicality, pp. 37-42. (2009).

8. Mitchell, R., Caglio, A., and Buur, J. Oops! Moments: Kinetic Material in Participatory Workshops. In Proc. NORDES - Nordic Design Research Conf., pp. 60-69, (2013).

9. Mitchell, R. An in your face interface: revisiting cyranoids as a revealing medium for interpersonal interaction. In: Proceedings of the 5th Student Interaction Design Research Conference (SIDeR): Flirting with the Future, pp. 56-59. Eindhoven, Eindhoven University of Technology (2009).

10. Mitchell, R., Gillespie, A., and O’Neill, B. Cyranic contraptions: using personality surrogates to explore ontologically and socially dynamic contexts. Desire'11, Proceedings of the Second Conference on Creativity and Innovation in Design pp. 199-210 ACM (2011).

11. Mitchell, R., Papadimitriou, A., You, Y., and Boer, L. Really Eating Together: A Kinetic Table To Synchronise Social Dining Experiences. In Proc. Augmented Human Conference, ACM (2015).

12. Shirky, C. Here Comes Everybody: The Power of Organizing Without Organizations. Penguin Press (2008). 